\title{
An 89 year old goes to hospital (with thanks to John Bowlby,1969)
}

\author{
Carol Worthington, PhD.
}

PSYCHOTHERAPIST, WELLINGTON

\begin{abstract}
In this reflection on living, dying and ageing, the author explores her encounter with different aspects of herself and others, evoked by a recent visit to hospital.
\end{abstract}

\section{Whakarāpopotonga}

I tēnei whakaarohanga whakapā atu ki ènei mea te koiora, te whakamatemate me te kaumātuahanga, ka tūhurahia e te kaituhi tōna tūtakitanga ki ōna me ōe êtahi atu tūmomo āhua rerekē i puea ake i muri mai i tētahi haerenga ki te hōhipera.

Key words: hospital; dying; euthanasia; life.

I continue to have doubts about submitting such a personal story, also wondering if it's too trivial to appeal, but then on reflection think that maybe it's a story needing to be told: how one's unconscious mind can carry one through a healing process in a way the conscious mind can not. The story is also age-related, which was one of the themes in the NZAP 2020 Conference, as in Susan Lugton's (unpublished) paper and Roy Bowden's Zoom meeting.

16 November 2020: “No, no, NO” I said, firmly and loudly, as I looked at my left leg, doubled up under me with toes beneath thigh, right leg in the shower where it had slipped on a tiny patch of the new shower cleaner I'd bought.

However, while denial is one of my family's favourite defences - enabling my father to sit under a sign reading "Cancer Ward" for a year while not "realising" his radiotherapy was for cancer - it obviously wasn't going to get me off the floor and round to my phone in the bedroom. Reality kicked in and I instinctively straightened the left leg and dragged myself to said phone. I rang for an ambulance, rang Jane of Casa de Wootton Cattery to look after Simba (my Burmese), and rang neighbours who needed to know, as I live in a semi-detached townhouse in a block of four. That was enough reality to deal with.

The ambulance arrived, and then for the first time pain kicked in. X-rays showed a series of horrendous cracks and breaks, with the kneecap also shattered. The next day I met the

\footnotetext{
Worthington, C. (2021). An 89 year old goes to hospital (with thanks to John Bowlby, 1969). Ata: Journal of

Psychotherapy Aotearoa New Zealand, 25(1), 107-111. https://doi.org/10.9791/ajpanz.2021.08
} 
surgeon and his anaesthetist. In my fantasy I would be brave and have the leg set under a local anaesthetic or epidural, but again reality intervened; the surgeon thought it would be the most difficult break he'd ever had to fix, so a general anaesthetic would be needed. As I did not expect to survive that, given my age, frailty and lung problems, I signed a form requesting no resuscitation if anything went wrong. I have always considered lethal injection the best way to die, if one must die, so I surrendered gracefully to the prick in the arm. I awakened to find a frame weighing over two kilos attached to my left leg, pinning the knee in an unmovable position and meaning I'd have to spend the next five or more weeks on my back when in bed.

As a firm advocate of euthanasia I had accepted that the fall and break had decided my fate, and that there was no point in enduring nausea caused by opiate-based painkillers, or the unpleasantness of physiotherapists exhorting one to painfully walk on frames, so I declared to the staff that I wished to be left alone and that when my son arrived from Australia he would be taking me home to die. "Would you like to see 'someone'?" was the anxious reply. "Damn it, I am 'someone'," I retorted, but finally gave in to their wish that I see the resident psychiatrist. I met this lovely lady from Brazil and tried to explain the difference between suicidal sadness and euthanasia. I think we agreed to disagree.

"I" with my euthanasia was ready to accept the inevitable, but the other "I" that speaks from the unconscious had made a different decision, one that I became aware of only much later. This is the "I" that Margot Solomon has so elegantly described as "thinking in the marrowbone" (Solomon, 2014). My "marrowbone" had opted for life and for a way to get me rested and looked after while a healing process could take place.

I don't recall much of the days after surgery which I spent in the Orthopaedic ward. After eight days I was transferred to Rehab - a misnomer if ever there was one. Rehab is situated as far away as is possible from the rest of the hospital, and when one finally reaches it, it's renamed the "Older Persons" ward. We are put where we'll be least trouble, can die gracefully, or just fade away. I regarded my poor twisted leg regretfully but remembered an amusing tale when I'd been in the OP ward in 2008, after a stroke. An elderly woman had been admitted to my cubicle who was very angry. I had asked what her problem was, to which she had replied, “I'm furious; I've been told I've got a broken leg. I don't know who broke it but it certainly wasn't me!” She was deadly serious.

It was only after some three weeks in hospital that I realised something strange had been happening to me. Evidently, my psyche had registered the whole experience as so traumatic (probably due to my age, and to the very real threat to my life) that I had entered a deep regression and did not know it! I needed to be nursed through it, I now realise. In this phase I gorged on potato crisps brought by my good friends and Helpers Extraordinaire, Ann Nation and Sandy Tustin, assisted by Sue Young and Sophia Jensen (members of our monthly Reading Group), and Elisabeth Stubbs.

I had with me a black and white striped blanket the cat sometimes slept on, and in this regressed phase it became a transitional object. Winnicott (1971) describes the transitional object as something between the sucked thumb and the teddy bear - the first possession - which the child uses to ward off anxiety, especially when trying to sleep. It can be a piece of wool, a blanket, really any object, but it must never be washed or changed. My blanket and a blue jersey I "had" to wear at night became such objects. I gave my blanket a name, 
Stripey, talked to it, snuggled it round my neck and generally soothed myself with it before going to sleep. My jersey and my Stripey, they comforted me.

To make the most embarrassing confession of all, while regressed I poo-ed in my bed! Admittedly the nurses dished out laxatives like there was no tomorrow, so eventually the dam broke, but I recall enjoying the soothing sensation of warm unmentionables accumulating round my body. I did this - only once! - without any sense of shame, until the nurses discovered it and were shocked and dismayed. I certainly felt shame then. I must admit though, I'm horrified in retrospect that a well-analysed psychotherapist could ever have entered such a regressed state. What would the Reading Group have made of that if they'd known! I do know that during this phase I had visitors and presumably I talked to them normally, and they did not notice anything wrong? I was aware that I found it hard to "make" conversation, and was glad when people departed.

The first inkling that I'd been in such a state occurred suddenly: a wave washed up on the shore of my psyche carrying an idea with it - I had a hand and maybe that hand could rearrange the pillows behind my head, I didn't have to ask the nurses to do it for me! This truly radical idea led me to cautiously put my hand on the pillows and yes, I could move them. With some effort I could also reach the water jug on my trolley and pour a drink! Another wave rolled ashore - there was a heater, heaters have controls, and maybe my hand could reach those controls and switch the heater on! And I could! Let there be warmth! For goodness knows how many days I had felt terribly cold, and had the paranoid fantasy that "they" wanted to freeze us to death. Now I had found some limited control over my surroundings. It felt as if there was a whole new world to be discovered, and I wonder now if this is how a baby feels when it starts to become aware of its surroundings.

A third wave ushered in the awareness of a wonderful book, brought by cat-lady Jane, called Enigma (Harris, 1995), a novel based on the group at Bletchley Park in UK, where they broke the Enigma code used by the Germans in World War Two. Like a child who wants the same story read over and over, I read and re-read Enigma. To be fair, to a non-mathematician it's a difficult novel, but I don't think that was my only reason for reading it at least five times. I devoured the book as I had devoured the potato crisps, refusing to read anything else. This clinging to a familiar object that must not change is also an aspect of the transitional object described by Winnicott, the book being like the blue jersey and the blanket. It all also reminded me again of the stroke in 2008 , when I'd spent the first two terrifying days and nights compulsively spelling "supercalifragilisticexpialidocious" in an effort to hold my psyche together and reassure myself there was some brain function. Holding the self together is one function of the transitional object.

I was very glad to emerge from this regressed state and to become more aware of what was going on around me. The OP/Rehab ward is not a very pleasant place to be in, surrounded as one is by people in various stages of dementia and senility. We had a convict with early stage dementia (and his two security guards, of whom I was more afraid than of him), and a woman who just wanted to walk round the TV lounge kissing everyone - some twenty times per day. Another woman told me her life story over and over, flatly refusing to consider she'd been hospitalised for memory loss. The convict and the kissing lady spent much of their day closely examining objects they might once have used, such as door knobs and small objects, desperately trying to recall some vestige of a familiarity they had once known. It was frightening and sad to watch. My packet of potato crisps was one such object, much to my 
dismay. This terrible loss of familiarity is a path some of us will tread, as the well-known gradually becomes unrecognisable and meaningless.

Most nurses seemed to cope by acting as if nothing much was wrong. However, one tiny Chinese nurse wore a face that was like a stone wall, betraying no emotions. Her lips were tightly drawn and she looked as though she hated everyone. Worried about her, one night I asked, as she was putting me to bed, what part of China she came from, as I had been in China myself in 1989, the year of Tiananmen Square. She looked startled but not exactly unfriendly as she said she came from way down south. I said that was exactly where I'd been, south in Xiaoquin! I remembered my husband and I being surrounded by peasants at a night market all begging us to help them develop their English, and laughing uproariously when I made a ridiculously low bid for an expensive object I didn't want. "Lovely people, awful government," I said as I told her this story. To my surprise her face burst into a lovely smile and then into tears, and she threw her arms round me as we both wept. "China broken," was all she said, and I dared not ask about terrible losses she had obviously endured. It was a moment I shall never forget, never to be repeated, though she did offer a faint smile if our paths crossed again. Parenthetically, we might reflect on this other side of China, in view of the anti-China sentiments bandied about by politicians today.

My son in Australia had been ringing me every day from Perth, where he lives and works, and as Christmas approached and his exit from quarantine neared, my thoughts about "going home to die" gradually changed into a very tentative possibility of "going home to recover." Comin' for to carry me home! While awaiting Tim's arrival on Christmas Day I listened to the physiotherapists, tried desperately with varying degrees of success to walk on their various frames, and generally prepared to depart after Christmas. The hospital wanted me to stay another two weeks but Tim and I had agreed that the depressing impingements of the OP ward were becoming too much for me. I discharged myself on 5 January, the day before my ninetieth birthday, and enjoyed celebrating 6 January with my son and my nonsenile friends.

The cat and I are now alone at home, facing an uncertain future. His future depends on my existence and I will not leave him behind. How lucky he is not to know of my ruminations about our future. My leg remains weak and twisted and I am dependent on a walking frame. As the weeks pass I shall have much time to decide whether this will slowly become a life that can be lived, or whether it is simply a time-passing existence, way beyond its use-by date. One defence has never left me; the feeling that all this is not actually real, it's happening to "the woman". But as my analyst once said, we all need our defences.

\section{References}

Bowlby, J. (1969). Attachment and Loss (Vol.1). Hogarth Press.

Harris, R. (1995). Enigma. Arrow Books.

Solomon, M. (2014). Reverie and Reflection: thinking in the marrowbone. Ata: Journal of

Psychotherapy Aotearoa New Zealand, 18, (1) 11-21.

Winnicott, D. (1971). Playing and Reality. Penguin Books.

Worthington, C. (1999). Some aspects of projective identification: Three clinical observations. 


\section{CAROL WORTHINGTON}

Forum: The Journal of the New Zealand Association of Psychotherapists, 5, 32-38.

Worthington, C. (2010). Fragment of a therapy: Experiences with psychosis. Forum: The Journal of the New Zealand Association of Psychotherapists, 15, 53-61.

Worthington, C. (2018, August). Address from an Elder at the Wellington Branch of NZAP. NZAP

Newsletter, 44-55.

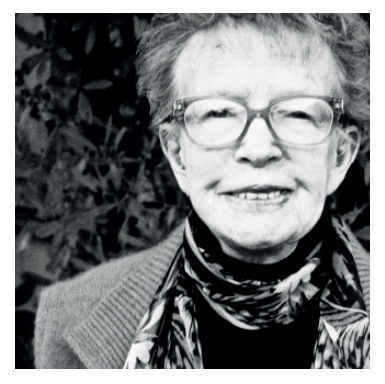

Carol Worthington has been a practising psychoanalytic psychotherapist for some 40 years; she holds a Ph.D. from Massey University (1977) and was a registered psychologist and member of the NZ Psychologists Association and of NZAP. She retired at Christmas 2019. Carol lives alone with a somewhat radical cat, the only surviving one of three. Before a fall in 2016, followed by pneumonia, she had been a keen gardener and an avid overseas traveller. She still writes letters to the Editor of the Dominion Post on political subjects, and has also published articles in the Ata Journal (when it was named Forum), in 1999 and 2010. Carol was asked by the Wellington Branch of NZAP to present the story of how she became a psychotherapist, and this later appeared in the NZAP Newsletter (2018). 